\title{
IoT-Based Smart Library Seat Occupancy and Reservation System using RFID and FSR Technologies for South African Universities of Technology
}

\author{
Magauwane R. Maepa \\ Department of Computer Science \\ Tshwane University of Technology \\ Private Bag X680, Pretoria, 0001, South Africa \\ MaepaMR@tut.ac.za
}

\author{
Michael N. Moeti \\ Department of Computer Science \\ Tshwane University of Technology \\ Private Bag X680, Pretoria, 0001, South Africa \\ MoetiMN@tut.ac.za
}

\begin{abstract}
The rising interest in Internet of Things (IoT) technologies and IoT-based systems worldwide, have revolutionized the normal way of doing business, especially in institutions of higher learning. One of the major challenges within academic institutions is the management of space in their libraries, allowing users to book or reserve a seat for a particular time. It is common to find students and staff complaining daily about how exhausting it is to find a space in the library. This is because one needs to physically walk and look for a vacant space for study, and this challenge has raised the need for a technological solution that is smart. Literature found that most smart library systems focused on seat occupancy detection and book reservation, whereas only a few smart library systems were developed in South Africa (SA). As far as could be established, however, there is a gap in the literature on seat reservation based on estimated arrival time, and reliable seat occupancy status, which needs to be filled. This paper aims to develop an IoT-based smart library seat occupancy and reservation (IoT-SLSOR) prototype, using the Radio Frequency Identification (RFID) and Force Sensitive Resistor (FSR) technologies. The choice of the prototype, as an innovative solution for Universities of Technology in South Africa (SA) was made because of its features and functionalities that improve transparency and builds a relationship between library users and their study facilities. Using this prototype, they would get real time access to their library seat occupancy status, and this would enable them to reserve seats online. The developed prototype was piloted using students and staff members at Tshwane University of Technology (TUT), to prove the accuracy and feasibility
\end{abstract}

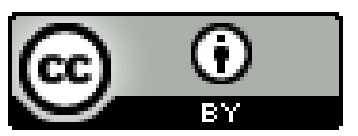

This work is licensed under a Creative Commons Attribution International 4.0 License icARTi '21, December 9-10, 2021, Virtual Event, Mauritius (C) 2021 Copyright held by the owner/author(s). ACM ISBN 978-1-4503-8575-6/21/12. https://doi.org/10.1145/3487923.3487933 of the research objectives. The results, using the prototype revealed an accuracy rate of approximately 99 percent.

CCS Concepts: • Internet of Things (IoT) $\rightarrow$ Smart Library; Seat Occupancy and Reservation; - Radio Frequency Identification (RFID); • Force Sensitive Resistor (FSR);

Keywords: Smart Library seat occupancy, IoT-based seat reservations, library seat management

\section{ACM Reference Format:}

Magauwane R. Maepa and Michael N. Moeti. 2021. IoT-Based Smart Library Seat Occupancy and Reservation System using RFID and FSR Technologies for South African Universities of Technology . In International Conference on Artificial Intelligence and its Applications (icARTi '21), December 9-10, 2021, Virtual Event, Mauritius. ACM, New York, NY, USA, 8 pages. https://doi.org/10.1145/3487923. 3487933

\section{Introduction}

Since the introduction of Internet of Things (IoT) technology in everyday human life, there has been a significant change in the way activities are performed worldwide [14]. The educational sector has not escaped this phenomenon. According to Bayani et al. [4], libraries also face innovative challenges, concerns and opportunities for enhancement owing to technological growth. The authors also stated that traditional library management systems are not considered to be smart systems, regardless of them using Radio Frequency Identification (RFID) barcodes in the various administrative processes. Hence, IoT-based smart libraries could afford green environmental protection while achieving interconnection, and they are also more effective and convenient compared to traditional libraries [6]. Thus, a wide range of smart library systems worldwide has been developed using IoT and Sensor technologies, but not in SA.

One of the major problems found at institutions across the world, is the challenge of looking for a vacant seat in their libraries due to limited space capacity $[9,13,16]$. This is caused by the number of students' intake at universities having increased significantly, whereas amenities, such as libraries, are not enhanced to ensure better service [7]. The 
challenge of seat occupancy and reservation in the library study sections has increasingly posed the need for smart solutions. This could also be possible with IoT, as it enables the real, digital, and virtual to converge to develop smart surroundings that make energy, transport, cities, and many other areas more intelligent [5]. IoT describes a system that connects daily things embedded with electronics, software and sensors to the Internet, enabling them to gather and exchange data [1]. According to Upala et al. [14], the challenge of looking for a vacant seat could lead to students spending needless time and energy searching for an available seat in the library study area. Thus, finding a study seat in the library study areas during test weeks and exams becomes very challenging and time consuming, as there is no online collaborative support system [9].

The lack of an effective smart system inconveniences students as they sometimes come all the way from their residence to study, only to find that the study sections are fully occupied, or in-use [14]. Some students place objects on library seats as a form of seat reservation. This practice frustrates students and librarians, which leads to limited seats. In some cases, students stand in long queues waiting for an available seat in the library study sections. The time spent looking for a seat, or waiting for an available seat, would be beneficial if used rather to do work. [7]. Although several studies have been conducted in other countries regarding smart libraries, only a few studies were conducted in South Africa. Most of these studies were focused on helping students find available books and reserving them online, whereas only a few were on seat reservation and occupancy using IoT. Hence, there was a need to enable students to check the status of seat availability in the library study sections online, and reserve a seat, if needed.

In this paper, we discuss the design and development of an IoT-Based smart library seat occupancy and reservation (IoTSLSOR) prototype using the FSR and RFID Technologies. The developed prototype consists of an IoT module that is used to monitor and signify the state of availability of each seat in the library study areas. An application was also provided. which enables end users to check the availability of seats in the study area and to reserve a seat, based on their estimated arrival time. This can be done anywhere and at any time, with the assistance of an IoT-based interconnected system. The developed prototype could be helpful for management to make strategic decisions. and develop a more efficient and effective library environment, as it provides the functionality to measure the number of visits, identify frequent library users, and which library areas were occupied [14].

The rest of this paper is structured as follows: Section 2 provides an outline of the related work; Section 3 highlights the Design Science Research Method. Then, conclusions are drawn in Section 4.

\section{Related Work}

Recently, there has been an increasing amount of research done on solving the problem of seat occupancy in Similar to Hoang et al. [9], the library study sections. For example, Upala et al. [14] constructed an IoT setting in an academic library embedded with the security parameter of "face recognition" for user identification within library management, supporting library space management, such as study room occupancy service using IoT applications. Torres et al. [13] employed a library seat occupancy counter to gather daily counts over time that would identify patterns in student preferences for study spaces and would use that information to improve several library services. The authors employed Microsoft Paint (MS Paint), Excel, and Qualtrics (Survey and researching tool). However, their study does not report how students engaged with space, and it also requires student workers to manually enter the number of students occupying seats, and their preference to get daily counts.

The problem of library seat management was also addressed by Daniel et al. [7]. They presented the design and execution of a resolution merging hardware and web application that permitted students and librarians to authenticate the identity of library seat inhabitants, and the occupancy status of the library seats anywhere and at any time over the Internet, using their devices, or on a display system, at the library entrance. Their prototype system limited time spent checking for an available seat, and phone calls received or made by students in search of their fellow students while in the library. However, there was no privacy or visibility functionality integrated in their Web Application. Nevertheless, library users could not reserve a seat; their system only permitted seat occupancy and monitoring. They developed a prototype of smart library seat occupancy and an information system using pressure (force-sensing resistor) and Radio Frequency Identification (RFID) sensors for library seats. This system sends the real-time seat utilization status to the web application. They suggested that future smart library systems should have a function to allow a seat occupant to take a break for a few minutes (reserve the seat), while in the library. This is the gap that the researcher hopes to fill.

Yahaya et al. [16] constructed a Seat Occupancy Detector system, similar to that of Hoang et al. [9], using capacitance sensors as an innovative method to differentiate the seats' occupancy by either a subject or an object. Both their systems were developed using a Raspberry $\mathrm{Pi}$ as the main controller, integrated into a Wi-Fi module, along with a capacitance sensor chip. Their projects were intended to ease the congestion, especially during, or before a test and exam week Their results were unreliable, however, as they failed to distinguish whether the seat had been occupied by a person or an object, but they nevertheless showed the seat occupancy status. Hence, they point out that there is a need to 
improve their analytical algorithms to accurately distinguish the occupancy detection status. Alam et al. [3] presented an IoT-based biometric public transport system, which was displayed on a device placed at the entrance of a bus. In their paper, students, or other stakeholders, could book an empty seat after being authorized by the device. The device presented the outline of the seat, indicating the booked or empty seat status by controlling an LED array, and the total seats and number of empty seats were displayed in an LCD screen.

\section{The Design Science Research Method}

This paper employed the Design Science Research (DSR) Methodology, and the process was adopted from a problemcentered approach. According to Peffers et al. [12], DSR creates and evaluates IT artifacts intended to solve identified organizational problems. DSR involves a rigorous process to design artifacts to solve observed problems, to make research contributions, to evaluate the designs, and to communicate the results to appropriate audiences. Such artifacts may include constructs, models, methods, and instantiations.

Figure 1 illustrates the DSRM process for an IoT-SLSOR prototype from a problem-centered research approach.

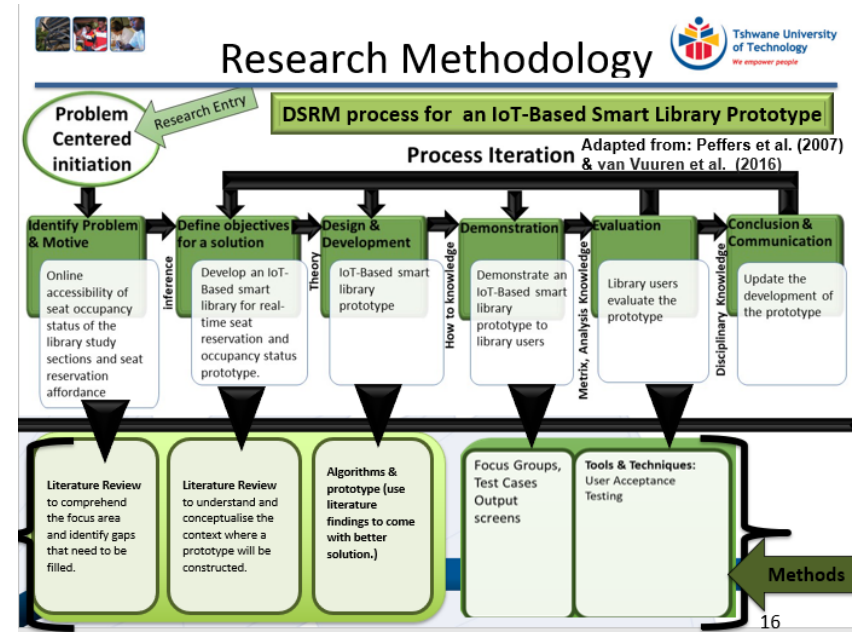

Figure 1. DSRM process for an IoT-SLSOR Prototype (Adapted from: $[12,15]$ )

\subsection{Step 1: Problem identification and motivation}

The limited space capacity, due to a lack of infrastructure, could lead to students devoting needless time and energy searching for an available seat in the library study sections. Thus, it causes stress on students who come all the way from their residence to the campus to study, only to find that all seats in the library study sections are fully occupied [9]. Hence, the time and energy spent looking for a seat, or waiting for an available seat, would be better utilized to do their work [7]. The challenge of reserving or occupying a vacant seat in the library study sections has posed the need to enable students to check the seat occupancy status and reserve seats online at their convenience. Therefore, the need for smart solutions triggered the development of an IoT-Based Smart Library system.

\subsection{Step 2: Objective of the solution}

The objective was to develop an IoT-Based smart library system to provide students the functionality of reserving a seat online. and checking the seat availability status of the library study sections at South African Universities. To achieve this, the researcher reviewed previously published papers, articles and journals related to this topic. This review of previously papers helped the researcher find out what other researchers had identified about seat occupancy and reservation systems, the current operations of SA libraries, and the gaps that still need to be filled. In addition, previous research that described characteristics of a smart library, highlighting the advantages and disadvantages, were explored to further understand the real context.

\subsection{Step 3: Design and Development}

This subsection discusses the activities that were setup by the required hardware and software used for the development of the proposed IoT-SLSOR prototype.

3.3.1 Hardware Design. The proposed IoT-SLSOR prototype used several types of hardware, such as a RFID card reader, FSR sensor, Raspberry Pi, LCD display, Application Server, and Database Server etc. There were several types of software that were used for this proposed prototype, which include MySQL, C++ IDE, PHP and XAMPP. C++ and IDE software are used to program or communicate between the sensors and the Raspberry Pi. PHP and XAMPP software were used for the development of the interface and database of the proposed Smart Library system.

In this proposed prototype, the FSR sensors are used as input devices, and LCD screens and smart phones are used as output devices. The FSR sensors will be placed under the library seat to detect the presence and absence of the occupants. Whenever a student occupies the seat in the library study section, the LCD display board, which will be placed at the entrance of each study section, will provide information about the number of seats available in each study section. The students could also check the same information about the status of the library using their smart phones at their place of comfort. The RFID card reader identifies the student. and the FSR sensor will detect the presence of a human being, or object, and send the data to the database through a Wi-Fi connection. The student number, seat number, date, and time of when the student occupies and leaves the study section seat, are recorded in the database and are accessed through the interface provided by the proposed IoT-SLSOR prototype. 
The usability and performance of the prototype for the proposed IoT-SLSOR prototype was tested to ensure that the system met all the specified functional and non-functional requirements, with no technical errors identified using User Acceptance Testing.

The FSR sensor and RFID card reader are connected to the Raspberry Pi. According to Bayani et al. [4], RFID refers to a type of electronic-tag device that can interact with the environment, and FSR helps to establish the non-centralized network between nodes and sending data to the gateway. RFID provides unique identification of the objects and enables tracking of them [4]. The minicomputer will send the data received from the sensors to the MySQL database whenever a student occupies or leaves the seat, and the data will constantly be updated on the database server. The Application server, which will use PHP and XAMPP to design the interface, will get data from the database server, and this information will be shown on the LCD display and accessed using any device with an internet connection.

Figure 2 depicts the interaction among the main elements of an IoT-Based Smart Library seat occupancy and reservation (IoT-SLSOR) prototype.

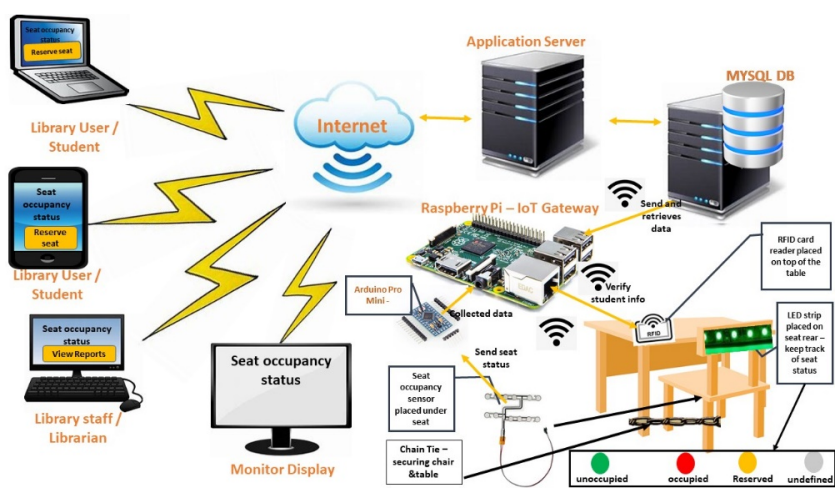

Figure 2. Block Diagram of the IoT-SLSOR prototype.

3.3.2 IoT-SLSOR prototype System Architecture. The researcher utilized information obtained from literature review results to develop a prototype, which consists of five layers: The Perception Layer, Network Layer, Data Access Layer, Application Layer and View Layer. The web application allows library users to view the occupied seat, or unoccupied seats, and reserve their desired seat. The library staff can use the system to view the seat availability status and register new library users. User Acceptance testing methods were used to evaluate the system usability and performance to enable the successful usability of an IoT-Based Smart Library prototype, and performance issues were addressed. The developed prototype will need to be constantly improved based on emerging performance needs.

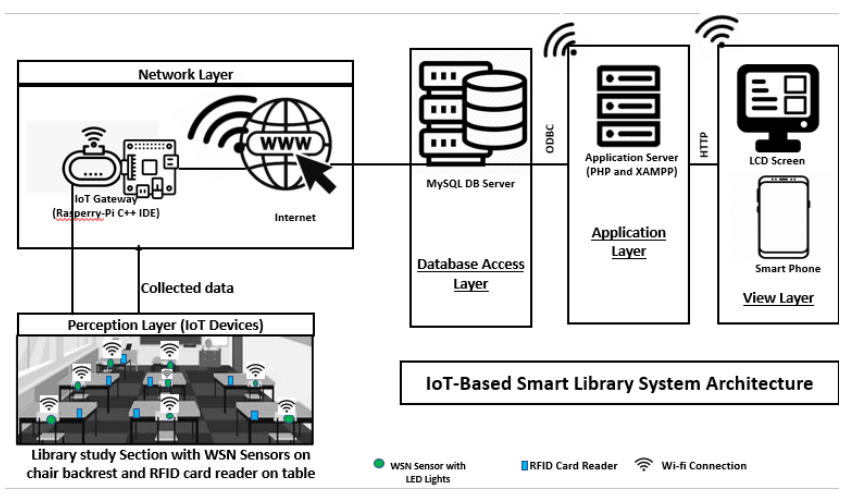

Figure 3. IoT-SLSOR system architecture.

3.3.3 IoT-SLSOR Web Application Design. The artifact is an IoT-based smart library seat occupancy and reservation prototype. It collects and maintains information about library study sections seats, library users, and library staff (Librarian). The proposed application consists of three (3) components:

- Library Information Module (LIM) - collects and maintains information about the SA University of Technology libraries and their study sections, library staff and the library users.

- Seat Occupancy and Reservation Module (SORM) captures information about various seats situated in the library study sections, including seat numbers, location, and availability status.

- IoT module - monitors and indicates the state of availability of each seat in the library study areas.

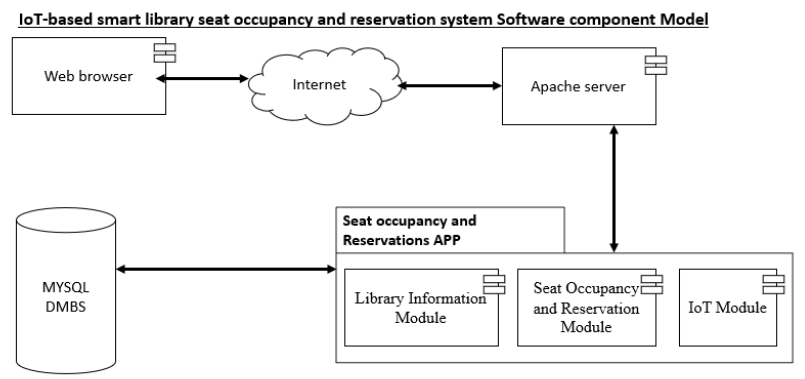

Figure 4. IoT-SLSOR prototype software component model.

3.3.4 IoT-SLSOR prototype description. The IoT-SLSOR prototype allows students to check the status of the library anywhere, anytime utilizing their mobile phones or any device with internet access. It ensures that reserved seats in the library study area are secured, and that users can reserve a seat according to their preferences. Everyone is allowed to view the library status and check the availability of seats, but only registered students are allowed to reserve library seats. This prototype acts as a link between the library users 
and the library staff (Librarian). The Librarian would have the ability to register new library users, view seat occupancy status and detailed reports. Figure 5 illustrates the Use case Model for the proposed prototype.

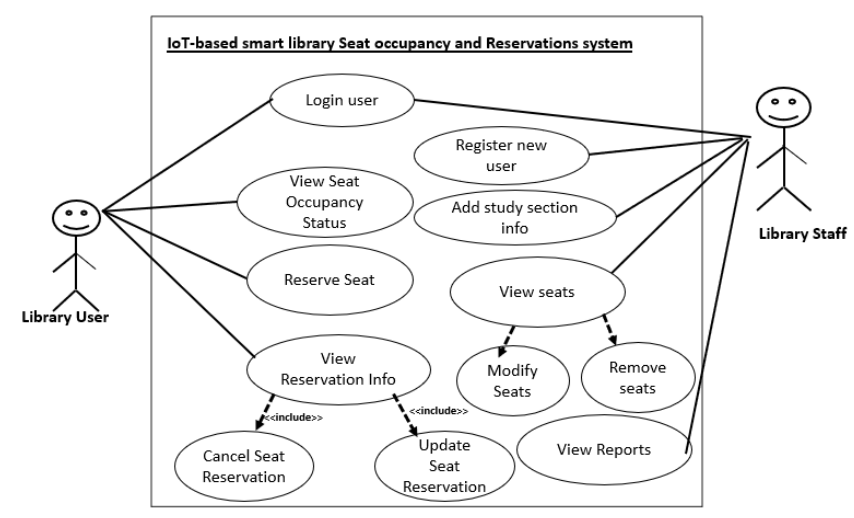

Figure 5. IoT-SLSOR prototype Use case Model.

3.3.5 Seat Behavior for the proposed IoT-SLSOR prototype. To reserve a seat, students have to login using both their student number as their username, and their password. After login, students could then select the desired study section, check available seats and choose a seat to reserve. A seat can only be reserved for 10 minutes, and if the $10 \mathrm{~min}$ utes elapses without the student occupying the seat, the seat will revert to unoccupied status. Unoccupied seats are presented by a green color, undefined seat by a grey color, reserved seats by an orange color, and occupied seats by a red color, respectively. When a student occupies a seat, the sensor will detect that some object is present, and sends the status to Raspberry Pi which then will be reflected to the user in the mobile application. The total procedure of booking and leaving a particular seat, and occupying a seat in the study section, will be clarified with the assistance of the flowchart in Figure 6 below. Students can only reserve or occupy one seat at the time.

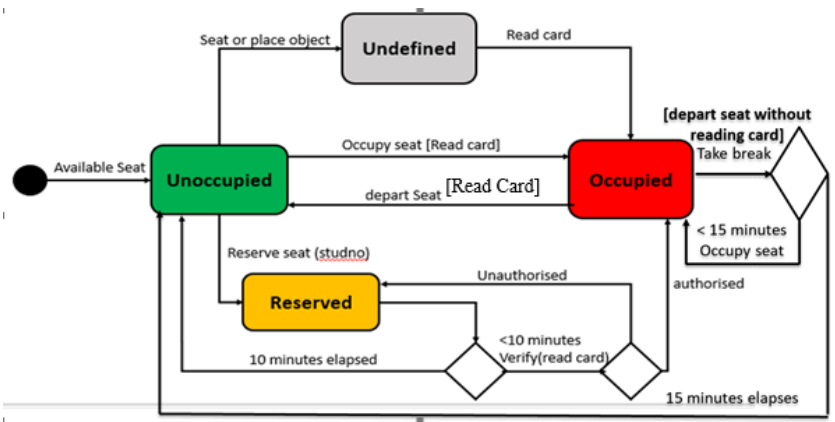

Figure 6. IoT-SLSOR prototype Seat Behavior flowchart.

\subsection{Step 4: Demonstration}

After developing an IoT-SLSOR prototype, the artifact could be widely adapted for use by the libraries of higher institutions. The researchers will explain the functions of the prototype and its applicability in a library setting to a focus group and provide screenshots of several output screens. The proposed smart library prototype could also help management to make strategic decisions and develop a more efficient and effective library environment, because it provides the functionality to extract several reports, such as the number of visits, frequent library users, which library areas were occupied. This solution was implemented using inexpensive and simple sensors to collect the required data of the library usage.

Figure 7 below displays the Index page, which is the first page that is shown when launched on the client's browser. It is a Welcome/Login page, whereby both the registered library user and the librarians are required to log into their accounts.

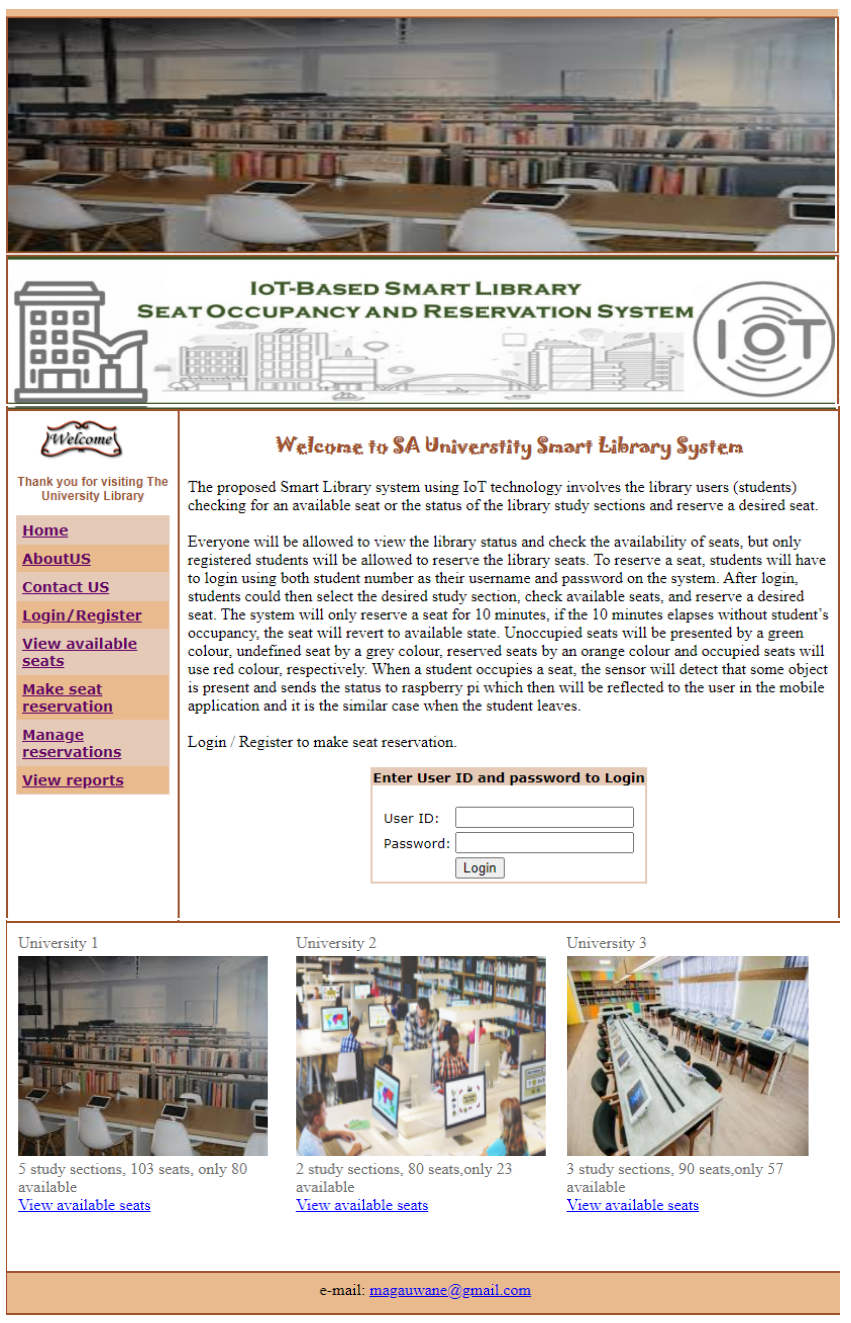

Figure 7. The index Page 
Figure 8 below shows the view vacant page that is returned after successful login, which displays seat occupancy status in detail per library study section of the university of technology where the library user is enrolled. After login, students could then select the desired study section, check available seats, and choose a seat to reserve. As the seat can only be reserved for 10 minutes, if the 10 minutes elapses without the student occupying the seat, the seat will revert to available status. Whenever a library user/object is on the seat (application of pressure only), the color representation of that seat on the web application changes to grey (Undefined). After reading the student card, it changes to red (occupied). If no pressure and tag/ID information is detected, the program will show the seat as unoccupied, using green color.

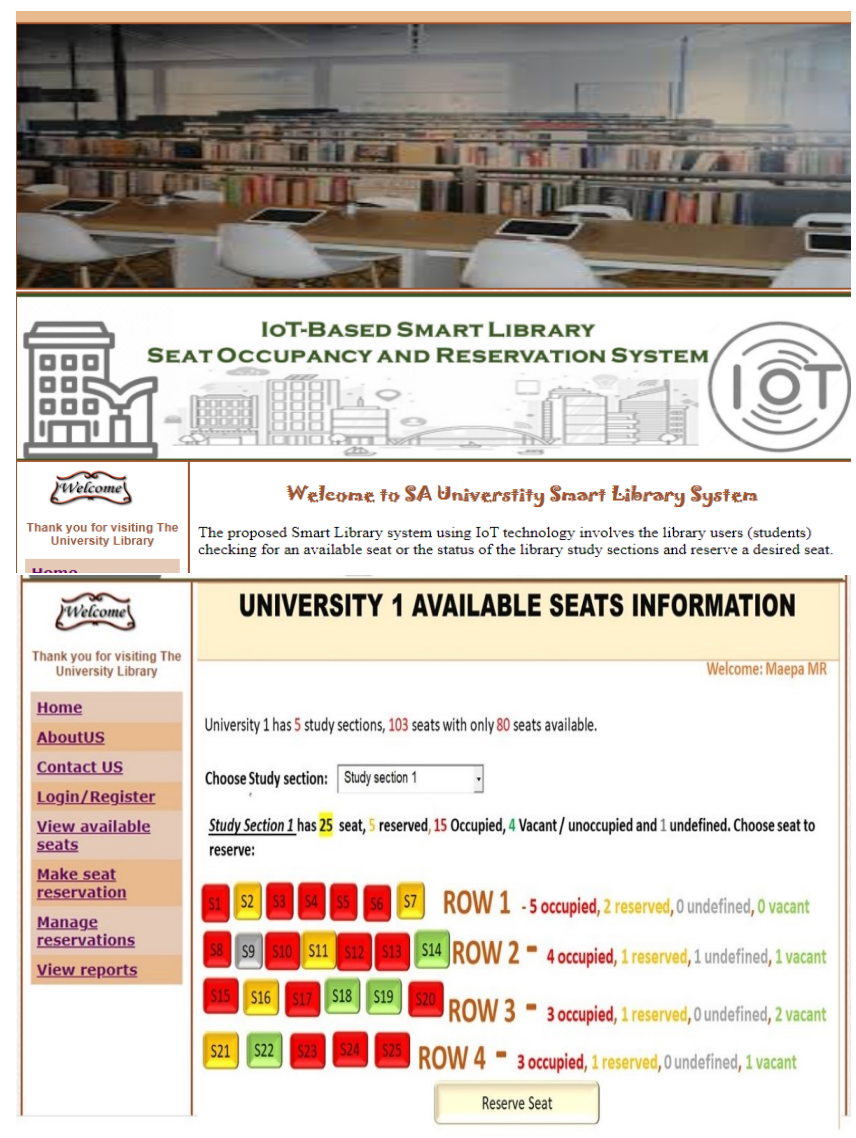

Figure 8. View vacant seats Page

\subsection{Step 5: Evaluation}

The proposed prototype was evaluated to determine the usability and the performance, and to ensure that all requirements were accomplished. The User Acceptance Test (UAT) was conducted to ensure that the prototype can handle the required tasks according to specifications, and to determine whether it satisfies the acceptance criteria of the users. To evaluate the user acceptance test for the proposed IoT-SLSOR prototype, it was evaluated by approximately 25 respondents. The experiment was conducted based on a demonstration given to the respondents on how the system works.

Then, they were required to discover the different system capabilities such as:

- Login as student / librarian.

- Register student.

- View seat occupancy status.

- Reserve unoccupied seat

- View, update or cancel reservation.

- View reports

\subsection{Step 6: Communication}

One of the major problems found at institutions across the world is the challenge of looking for a vacant seat in the libraries due to limited space capacity, which could lead to students wasting time and energy searching for an available seat in the library study sections. To address this issue, this paper discussed the design and implementation of an IoT-based smart library seat occupancy and reservation prototype and analyzed its usability. According to the findings of this study, this problem was successfully resolved, as 99.5 percent of respondents agreed, and strongly agreed, that the system will enhance academic excellence because it successfully reduced time spent on looking or waiting for an available seat. This objective was attained, considering that the participants all agreed that the application also helped them with real time library seat occupancy status and flexibility, by allowing them to reserve seats anytime, anywhere, if they are connected to the internet. The respondents agreed that they will use IoT-SLSOR system to check the status of the library seats and to reserve seats. The library staff also appreciated features such as the functionality to measure the number of visits, to identify frequent library users and, which library areas were occupied. Ninety percent $(90 \%)$ of the respondents agreed that they became familiar with the application easily, and that they enjoyed using the application. The focus of this paper was only on the design and development of an IoT-based smart library seat occupancy and reservation system, which provides students and staff the ability to check seat availability status and reserve seats online. Consequently, the paper excludes other library management systems, such as providing support for teaching and learning activities and reserving books etc. The scope of the paper is limited to South African Universities of Technology, focusing only on study sections of these libraries. The proposed prototype could be updated accordingly, if needed, guided by the library user's suggestions and comments after system evaluations. 
Table 1. Paper technical objectives, methods, and deliverables

\begin{tabular}{|c|c|c|c|}
\hline Research Question & Research objectives & Method/ Technique/ Tools & Deliverables / outcomes \\
\hline $\begin{array}{l}\text { RQ1. How does the } \\
\text { traditional and con- } \\
\text { ventional library } \\
\text { system in South } \\
\text { Africa universities } \\
\text { operate? }\end{array}$ & $\begin{array}{l}\text { RO1. To compare the op- } \\
\text { eration of traditional and } \\
\text { conventional library sys- } \\
\text { tem in South Africa uni- } \\
\text { versities. }\end{array}$ & $\begin{array}{l}\text { Data Collection: } \\
\text { Literature Review }\end{array}$ & $\begin{array}{l}\text { Current operations at SA university } \\
\text { libraries. }\end{array}$ \\
\hline $\begin{array}{l}\text { RQ2. How does the ex- } \\
\text { isting library seat oc- } \\
\text { cupancy and reserva- } \\
\text { tion systems work? }\end{array}$ & $\begin{array}{l}\text { RO2. To analyze the ap- } \\
\text { plications and function- } \\
\text { alities of the existing IoT- } \\
\text { based seat occupation } \\
\text { and reservation systems. }\end{array}$ & $\begin{array}{l}\text { Data Collection: } \\
\text { Literature Review }\end{array}$ & $\begin{array}{l}\text { Previously proposed smart library } \\
\text { systems and their applications. } \\
\text { Characteristics, advantages, and dis- } \\
\text { advantages of the existing smart li- } \\
\text { brary applications. }\end{array}$ \\
\hline $\begin{array}{l}\text { RQ3. What are the } \\
\text { limitations of the seat } \\
\text { occupancy and reser- } \\
\text { vation systems? }\end{array}$ & $\begin{array}{l}\text { RO3. To identify the } \\
\text { limitations of the exist- } \\
\text { ing seat occupancy and } \\
\text { reservation systems. }\end{array}$ & $\begin{array}{l}\text { Data Collection: } \\
\text { Literature Review }\end{array}$ & $\begin{array}{l}\text { b. Limitations of the existing smart } \\
\text { library applications. }\end{array}$ \\
\hline $\begin{array}{l}\text { RQ4. How to develop } \\
\text { an IoT-based smart li- } \\
\text { brary seat occupancy } \\
\text { and reservation proto- } \\
\text { type? }\end{array}$ & $\begin{array}{l}\text { RO4. To implement an } \\
\text { IoT-Based smart library } \\
\text { seat occupancy and } \\
\text { reservation prototype. }\end{array}$ & $\begin{array}{l}\text { Data collection: } \\
\text { Literature review } \\
\text { Methods } \\
\text { DSRM process, Algorithm, } \\
\text { design and modelling (pro- } \\
\text { totype) } \\
\text { Hardware: } \\
\text { IoT technologies (FSR, RFID, } \\
\text { Raspberry Pi, LCD Display, } \\
\text { LED Lights, DB server, Wi- } \\
\text { Fi) Software: MySQL, C++ } \\
\text { IDE, PHP XAMPP }\end{array}$ & $\begin{array}{l}\text { Identify all activities required to re- } \\
\text { search, build, deploy, and maintain } \\
\text { the Smart library prototype. } \\
\text { A profound understanding into how } \\
\text { these limitations of seat occupancy } \\
\text { and reservation systems can be re- } \\
\text { solved using IoT technologies. } \\
\text { The advantages and disadvantages of } \\
\text { each method will be looked at and } \\
\text { having better performance than us- } \\
\text { ing each method separately. } \\
\text { The development of an IoT-Based } \\
\text { Smart library Seat occupancy and } \\
\text { reservation prototype. }\end{array}$ \\
\hline $\begin{array}{l}\text { RQ5. How to evaluate } \\
\text { the usability and per- } \\
\text { formance of the proto- } \\
\text { type? }\end{array}$ & $\begin{array}{l}\text { RO5. To evaluate the us- } \\
\text { ability and performance } \\
\text { of the prototype. }\end{array}$ & $\begin{array}{l}\text { Tools \& Techniques: } \\
\text { User Acceptance Testing }\end{array}$ & $\begin{array}{l}\text { Technological acceptance and stu- } \\
\text { dents and staff's engagement. } \\
\text { Technological improvements for } \\
\text { smart library and delivery. }\end{array}$ \\
\hline
\end{tabular}

\section{Conclusion and Future Work}

In this research paper, we have used IoT technologies, namely RFID and FSR, and proposed a smart library seat occupancy and reservation prototype that can easily be integrated into real time projects. The proposed prototype provides the ability to check the status of the library study section to see if there is still a seat available, or not, and allow seat reservation. IoT is an innovative technology that incorporates billions of smart objects into our daily life to enhance social, technical, and economic benefits, and can be used in any project. The above prototype provides the solution to overcome the issues such as finding the occupancy of library study-rooms and reducing manual effort to ensure that reserved seats in the library study area are secured, and that users can reserve a seat according to their preferences. There are several enhancements that can be made in the context of smart library, such as enforcing security on reserved seats using IoT technologies to ensure that the seats can only be utilized by authorized users. We can even adopt security access door strategy using RFID and sensor magnetic technologies to attach seats and tables. In this case, the seat will be released only if authorized users tag their card on an RFID reader. 


\section{References}

[1] Abdelrahman Abuarqoub, Hesham Abusaimeh, Mohammad Hammoudeh, Diaa Uliyan, Muhannad A Abu-Hashem, Sharefa Murad, Mudhafar Al-Jarrah, and Fayez Al-Fayez. 2017. A survey on internet of things enabled smart campus applications. In Proceedings of the International Conference on Future Networks and Distributed Systems. $1-7$.

[2] Mukhles Al-Ababneh. 2020. Linking ontology, epistemology and research methodology. Science \& Philosophy 8, 1 (2020), 75-91.

[3] Md Eftekhar Alam, Mohammed Abdul Kader, Rahala Parvin, Sharmin Sultana, Zinnia Sultana, and Sumaiya Deen Muhammad. 2021. IoT based bio-metric seat reservation and transport management system for university bus. In 2021 2nd International Conference on Robotics, Electrical and Signal Processing Techniques (ICREST). IEEE, 649-653.

[4] Majid Bayani, Alberto Segura, Marjorie Alvarado, and Mayra Loaiza. 2018. IoT-based library automation and monitoring system: developing an implementation framework of implementation. E-Ciencias de la Información 8, 1 (2018), 83-100.

[5] Diana-Iuliana BOBOC and Ştefania-Corina CEBUC. [n.d.]. Internet of Things (IoT). Database Systems fournal BOARD ([n. d.]), 100.

[6] A Larsan Aro Brian, L Arockiam, and PDSK Malarchelvi. 2014. An IOT based secured smart library system with NFC based book tracking. International fournal of Emerging Technology in Computer Science \& Electronics (IfETCSE) 11, 5 (2014), 18-21.

[7] Okoronkwo Chinomso Daniel, Visham Ramsurrun, and Amar Kumar Seeam. 2019. Smart library seat, occupant and occupancy information system, using pressure and RFID sensors. In 2019 Conference on Next Generation Computing Applications (NextComp). IEEE, 1-5.
[8] Hossein Hassani. 2017. Research methods in computer science: The challenges and issues. arXiv preprint arXiv:1703.04080 (2017).

[9] Nguyen Huy Hoang Huy, Gihan Hettiarachchi, Youngki Lee, and Rajesh Krishna Balan. 2016. Small scale deployment of seat occupancy detectors. In Proceedings of the 3rd International on Workshop on Physical Analytics. 25-30.

[10] John Kuada. 2012. Research methodology: A project guide for university students. Samfundslitteratur.

[11] Dietmar PF Möller. 2016. Guide to computing fundamentals in cyberphysical systems. Computer Communications and Networks. Springer, Heidelberg (2016).

[12] Ken Peffers, Tuure Tuunanen, Marcus A Rothenberger, and Samir Chatterjee. 2007. A design science research methodology for information systems research. Fournal of management information systems 24 , 3 (2007), 45-77.

[13] Ana Torres and Gavin Paul. 2019. Reaching maximum occupancy: What the numbers tell us about space and ways to improve services. Journal of Access Services 16, 2-3 (2019), 78-93.

[14] Maulik Upala and WK Wong. 2019. IoT solution for smart library using facial recognition. In IOP Conference Series: Materials Science and Engineering, Vol. 495. IOP Publishing, 012030.

[15] Joey Jansen van Vuuren, Louise Leenen, Marthie M Grobler, Ka Fai Peter Chan, and Zubeida C Khan. 2016. Morphological Ontology Design Engineering: A Methodology to Model Ill-Structured Problems. In Mixed Methods Research for Improved Scientific Study. IGI Global, 262291.

[16] Nursyeha Yahaya, Devika Sangaram, Salihin Mohammed Ali, and Aaron Tay. 2017. SMU Libraries: "Sensory" in library spaces. Singapore fournal of Library and Information Management 45 (2017), 61. 